\title{
Benefit of Adjuvant Chemotherapy After Radical Cystectomy for Treatment of Urothelial Carcinoma of the Bladder in the Elderly - An International Multicenter Study
}

Victor M. Schuettfort ${ }^{\mathrm{a}, \mathrm{b}}$, Benjamin Pradere ${ }^{\mathrm{a}, \mathrm{c}}$, Hadi Mostafaei ${ }^{\mathrm{a}, \mathrm{d}}$, Ekaterina Laukhtina ${ }^{\mathrm{a}, \mathrm{e}}$, Keiichiro Mori ${ }^{\mathrm{a}, \mathrm{f}}$, Fahad Quhal ${ }^{\mathrm{a}, \mathrm{g}}$, Reza Sari Motlagh ${ }^{\mathrm{a}}$, Michael Rink ${ }^{\mathrm{b}}$, Pierre I. Karakiewicz ${ }^{\mathrm{h}}$, Marina Deuker ${ }^{\mathrm{h}, \mathrm{i}}$, Marco Moschini ${ }^{\mathrm{j}, \mathrm{k}, \mathrm{l}}$, Lara Franziska Stolzenbach ${ }^{\mathrm{h}, \mathrm{m}}$, Quoc-Dien Trinh ${ }^{\mathrm{n}}$, Alberto Briganti ${ }^{\circ}$, David D'Andrea ${ }^{\mathrm{a}}$ and Shahrokh F. Shariat ${ }^{\mathrm{a}, \mathrm{e}, \mathrm{p}, \mathrm{q}, \mathrm{r}, \mathrm{s}, \mathrm{t}, \mathrm{u}, *}$

${ }^{a}$ Department of Urology, Comprehensive Cancer Center, Medical University of Vienna, Vienna, Austria

${ }^{\mathrm{b}}$ Department of Urology, University Medical Center Hamburg-Eppendorf, Hamburg, Germany

${ }^{\mathrm{c}}$ Department of Urology, University Hospital of Tours, Tours, France

${ }^{\mathrm{d}}$ Research Center for Evidence Based Medicine, Tabriz University of Medical Sciences, Tabriz, Iran

${ }^{\mathrm{e}}$ Institute for Urology and Reproductive Health, Sechenov University, Moscow, Russia

${ }^{\mathrm{f}}$ Department of Urology, The Jikei University School of Medicine, Tokyo, Japan

$\mathrm{g}^{\mathrm{g}}$ Department of Urology, King Fahad Specialist Hospital, Dammam, Saudi Arabia

${ }^{\mathrm{h}}$ Cancer Prognostics and Health Outcomes Unit, Division of Urology, University of Montreal Health Center, Montreal, QC, Canada

${ }^{\mathrm{i}}$ Department of Urology, University Hospital Frankfurt, Frankfurt, Germany

${ }^{\mathrm{j}}$ Department of Urology, Luzerner Kantonsspital, Lucerne, Switzerland

${ }^{\mathrm{k}}$ Department of Urology, Institut Mutualiste Montsouris, Paris, France

${ }^{1}$ Department of Urology and Division of Experimental Oncology, Urological Research Institute, Vita-Salute San Raffaele University, IRCCS San Raffaele Scientific Institute, Milan, Italy

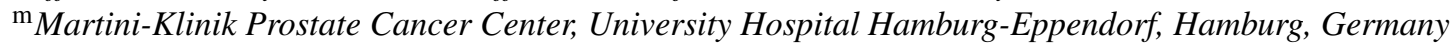

${ }^{\mathrm{n}}$ Division of Urological Surgery and Center for Surgery and Public Health, Brigham and Women's Hospital, Harvard Medical School, Boston, MA, USA

${ }^{\circ}$ Department of Urology, Urological Research Institute, Vita-Salute University, San Raffaele Scientific Institute, Milan, Italy

${ }^{\mathrm{p}}$ Division of Urology, Department of Special Surgery, Jordan University Hospital, The University of Jordan, Amman, Jordan

${ }^{\mathrm{q}}$ Department of Urology, Weill Cornell Medical College, New York, NY, USA

${ }^{\mathrm{r}}$ Department of Urology, University of Texas Southwestern, Dallas, TX, USA

${ }^{\mathrm{s}}$ Department of Urology, Hospital Motol, Second Faculty of Medicine, Charles University, Prague, Czech Republic

${ }^{\mathrm{t}}$ Karl Landsteiner Institute of Urology and Andrology, Vienna, Austria

${ }^{\mathrm{u}}$ European Association of Urology Research Foundation, Arnhem, Netherlands

\footnotetext{
${ }^{*}$ Correspondence to: Shahrokh F. Shariat MD, Department of Urology, Comprehensive Cancer Center, Vienna General Hospital, Medical University of Vienna, Währinger Gürtel 18-20, 1090,
}

Vienna, Austria. Tel.: +4314040026150; Fax: +4314040023320; contact: E-mail: shahrokh.shariat@meduniwien.ac.at. 
Received 11 September 2020

Accepted 3 January 2021

Pre-press 26 January 2021

Published 25 May 2021

\begin{abstract}
.
BACKGROUND: Radical cystectomy $(\mathrm{RC})$ is the standard treatment for muscle invasive bladder cancer, but approximately half of all patients will ultimately succumb to disease progression despite apparent cure with extirpative surgery. Elderly patients are at especially high risk of advanced disease and may benefit from perioperative systemic therapy.

OBJECTIVE: To assess the real-world benefit of adjuvant chemotherapy (AC) in patients $\geq 75$ years old.

METHODS: We retrospectively reviewed patients who underwent RC for non-metastatic urothelial carcinoma of the bladder (UCB) from 12 participating international medical institutions. Kaplan-Meier survival curves and Cox regression models were used to assess the association between age groups, administration of AC and oncological outcome parameters such as recurrence-free survival (RFS), cancer-specific survival (CSS) and overall survival (OS).

RESULTS: 4,335 patients were included in the analyses, of which 820 (18.9\%) were $\geq 75$ years old. These elderly patients had a higher rate of adverse pathologic features. In an univariable subgroup analysis in patients $\geq 75$ years with lymph node metastasis, 5-year OS was significantly higher in patients who had received AC (41\% vs. 30.9\%, $p=0.02)$. In a multivariable Cox model that was adjusted for several established outcome predictors, there was a significant favorable association between the administration of AC in elderly patients and OS, but no RFS or CSS.

CONCLUSION: In this large observational study, the administration of AC was associated with improved OS, but not RFS or CSS, in elderly patients treated with RC for UCB. This is of clinical importance, as elderly patients are more likely to have adverse pathologic features and experience worse survival outcomes. Treatment of UCB should include both a multidisciplinary approach and a geriatric evaluation to identify patients who are most likely to tolerate and benefit from AC.
\end{abstract}

Keywords: MIBC, NMIBC, bladder cancer, elderly, adjuvant chemotherapy, systemic therapy, transitional cell carcinoma

\section{INTRODUCTION}

Radical cystectomy (RC) is the standard treatment for muscle-invasive bladder cancer (MIBC); but due to its heterogeneous nature and high rate of occult metastases, approximately half of all patients will ultimately succumb to disease progression despite apparent cure with extirpative surgery [1-4]. There is an unmet need to provide reliable risk-stratification tools for patient selection towards perioperative systemic therapy [5], as biomarkers that add sufficient value on outcome prediction are still missing [6-13]. Furthermore, clinical stage is discrepant with final pathologic stage and only postoperative pathologic features offer the highest prognostic value [4, 13-15]. Still, due to the aggressiveness of MIBC, in all eligible patients, $\mathrm{RC}$ and cisplatin-based neoadjuvant chemotherapy (NAC) is considered as the standard of care, due to level one evidence demonstrating a netbenefit in overall survival (OS) and recurrence-free survival (RFS), relative to no NAC [3, 16, 17].

Adjuvant chemotherapy (AC) has frequently been favored over NAC as treatment decisions can be based on pathological staging, however, there are only weak data comparing the efficacy of both treatment modalities [18]. This could be especially true for older patients, as treating physicians may find the potential detrimental effect of NAC and the risk of overtreatment particularly disadvantageous in this specific group of patients [19]. As MIBC is considered more aggressive in the elderly population, older patients may therefore especially benefit from AC [20, 21]. However, only observational studies and meta-analyses have demonstrated a clear benefit to RFS and OS for the use of AC vs. surgery alone $[22,23]$. Multiple prospective studies failed to confirm its efficacy over deferred chemotherapy at time of recurrence due to poor accrual [24-26]. Patient selection for the use of AC is of highest importance, as especially patients with lymph node metastases and/or $\geq \mathrm{pT} 3$ disease seem to benefit from AC [5, $22,23,27,28]$. Older patients are known to be less likely to receive appropriate treatment for MIBC, including a less frequent administration of $\mathrm{AC}$, even though it has been demonstrated that they can tolerate platinum-based chemotherapy sufficiently well [29, 30]. However, the real-world benefit of AC among these patients remains poorly defined.

We hypothesized that administration of AC can improve survival outcomes in elderly patients treated with RC for urothelial carcinoma of the bladder (UCB). To test this hypothesis, we compared survival outcomes of patients treated with or without AC after $\mathrm{RC}$ in a large, international-multicenter study. We 
also conducted multiple subgroup analyses in order to evaluate which patients may particularly benefit from AC.

\section{METHODS}

\section{Subjects/patients}

\section{Patients selection}

This retrospective study included patients who underwent RC between 1990 and 2012 for nonmetastatic UCB from 12 participating international medical institutions. No patient received NAC or radiotherapy. All cases were histologically confirmed urothelial carcinoma of the bladder with only minor variant component, if any. Extent of lymph node dissection and the choice of urinary diversion were at the surgeon's discretion. Patients with any concomitant second malignancy other than UCB, concomitant upper urinary tract carcinoma or missing data were excluded. The study was approved by the local ethics committees at all participating institutions and informed consent for participation in future retrospective studies were obtained from all eligible patients (IRB 0698 26900).

All surgical specimens were processed according to standard pathological procedures as previously described [4]. All tumors were histologically confirmed to be UCB, staged according to the American Joint Committee on Cancer (AJCC) Staging Manual (8th edition) TNM classification and graded according to the 1973 World Health Organization grading system. The presence of concomitant carcinoma in situ (CIS) was defined as the presence of CIS in conjunction with another tumor other than CIS [31]. Pelvic lymph nodes were examined grossly, and all lymphoid tissue was submitted for histological examination. Positive soft tissue surgical margin was defined as the presence of tumor at inked areas of soft tissue on the RC specimen [32]. Urethral or ureteral margins were not considered as soft tissue surgical margins. Lymphovascular invasion was defined as the unequivocal presence of tumor cells within an endothelium-lined space without underlying muscular walls [33].

AC was defined as the administration of any chemotherapeutic agent started within three months of $\mathrm{RC}$ at the discretion of the treating physician and according to international guideline recommendations. No detailed information concerning the specific agents or number of cycles administered are available. Clinical and radiological follow-up was performed in accordance with institutional protocols. For most patient's physical examination, radiological imaging, and urine cytology were obtained every three months for two years, then semiannually between the second and the fifth year. After five years, annual follow up was performed. Tumor recurrence was defined as the occurrence of locoregional recurrence or distant metastasis on radiological imaging. Cause of death was abstracted from medical charts end/or from death certificates [34]. Patient data were collected and stored in a common anonymized dataset.

\section{Statistical analysis}

Report of categorical variables included frequencies and proportions. Reporting of continuous coded variables focused on medians and interquartile ranges (IQR). The cohort was split into two cohort according to their age group $(<75$ years vs. $\geq 75$ years old at time of RC). With respect to these different age groups, group comparisons were performed using the chi-squared and Mann-Whitney U tests, as appropriate.

Kaplan-Meier survival curves and log-rank tests analyzed the association between age and oncological outcome parameters such as RFS, cancer-specific survival (CSS), and OS. The assumption of proportional hazards was assessed by Schoenfeld residuals plots. If conditions of non-proportional hazards were found, the Peto \& Peto modification of the GehanWilcoxon test was used instead of the log rank test for comparison of survival outcomes, as this test is also efficient when the proportional hazard assumption is violated [35]. Association between prognostic variables and RFS, cancer-specific survival (CSS) and OS were assessed in univariable and multivariable Cox regression models, if the assumption of proportional hazards was not violated. Clinical and pathologic tumor grade was excluded as an independent variable for all predictive models, since the vast majority of all RC patients had high grade UCB. All reported $p$-values were two-sided, and statistical significance was set at 0.05 . Statistical analyses were performed using R Version 3.6.3.

\section{RESULTS}

\section{Patient demographics}

Patient characteristics are displayed in Table 1. Median age of the entire cohort was 67.0 years (IQR 59.7-73.1) Elderly patients had significantly higher rates of adverse pathologic features such as 
Table 1

Association of age and Administration of Adjuvant Chemotherapy with Clinicopathologic Characteristics in 4,335 Patients Treated with Radical Cystectomy for Urothelial Carcinoma of the Bladder

\begin{tabular}{|c|c|c|c|c|c|c|c|c|}
\hline \multirow[t]{2}{*}{ Variable } & \multirow[t]{2}{*}{ Reference } & \multirow{2}{*}{$\begin{array}{c}\text { Overall } \\
\text { population } \\
\mathrm{N}(\%) \\
4335\end{array}$} & \multicolumn{2}{|c|}{$\begin{array}{l}\text { Overall population } \\
\text { stratified by age }\end{array}$} & \multirow[t]{2}{*}{$p$} & \multicolumn{2}{|c|}{$\begin{array}{c}\text { Patients } \geq 75 \text { years } \\
\text { stratified by use of } \mathrm{AC}\end{array}$} & \multirow[t]{2}{*}{$p$} \\
\hline & & & $\begin{array}{c}<75 \text { years } \\
3515(81.1)\end{array}$ & $\begin{array}{l}\geq 75 \text { years } \\
820(18.9)\end{array}$ & & $\begin{array}{c}\text { AC no } \\
718(87.6 \%)\end{array}$ & $\begin{array}{c}\text { AC yes } \\
102(12.4 \%)\end{array}$ & \\
\hline Gender & Male & $3464(79.9)$ & $2843(80.9)$ & $621(75.7)$ & 0.001 & $536(74.7)$ & $85(83.3)$ & 0.073 \\
\hline Thrombocytosis & yes & 476 (11) & $371(11)$ & $105(13)$ & 0.073 & $91(13)$ & $14(14)$ & 0.9 \\
\hline Hypoalbuminemia & yes & $627(14)$ & $472(13)$ & $155(19)$ & $<0.001$ & $139(19)$ & $16(16)$ & 0.5 \\
\hline Perioperative blood transfusion & yes & $1,143(26)$ & $929(26)$ & $214(26)$ & 0.9 & $187(26)$ & $27(26)$ & $>0.9$ \\
\hline \multirow[t]{3}{*}{ Clinical tumor grade } & Grade 2 & $43(1.0)$ & $42(1.2)$ & $1(0.1)$ & 0.005 & $1(0.1)$ & $0(0.0)$ & 0.73 \\
\hline & Grade 3 & $4156(95.9)$ & $3362(95.6)$ & $794(96.8)$ & & $693(96.5)$ & $101(99.0)$ & \\
\hline & NA & $136(3.1)$ & $111(3.2)$ & $25(3.0)$ & & $24(3.3)$ & $1(1.0)$ & \\
\hline \multirow{7}{*}{ Clinical tumor stage } & cTa & $141(3.3)$ & $121(3.4)$ & $20(2.4)$ & 0.011 & $17(2.4)$ & $3(2.9)$ & 0.025 \\
\hline & cTis & $308(7.1)$ & $253(7.2)$ & $55(6.7)$ & & $54(7.5)$ & $1(1.0)$ & \\
\hline & $\mathrm{cT} 1$ & $1078(24.9)$ & $896(25.5)$ & $182(22.2)$ & & $161(22.4)$ & $21(20.6)$ & \\
\hline & $\mathrm{cT} 2$ & $2372(54.7)$ & $1896(53.9)$ & $476(58.0)$ & & $412(57.4)$ & $64(62.7)$ & \\
\hline & cT3 & $171(3.9)$ & $129(3.7)$ & $42(5.1)$ & & $33(4.6)$ & $9(8.8)$ & \\
\hline & cT4 & $129(3.0)$ & $109(3.1)$ & $20(2.4)$ & & $17(2.4)$ & $3(2.9)$ & \\
\hline & NA & $136(3.1)$ & $111(3.2)$ & $25(3.0)$ & & $24(3.3)$ & $1(1.0)$ & \\
\hline \multirow[t]{3}{*}{ Pathological tumor grade } & Grade 1 & $227(5.2)$ & $197(5.6)$ & $30(3.7)$ & 0.024 & $29(4.0)$ & $1(1.0)$ & 0.194 \\
\hline & Grade 2 & $54(1.2)$ & $48(1.4)$ & $6(0.7)$ & & $6(0.8)$ & $0(0.0)$ & \\
\hline & Grade 3 & $4054(93.5)$ & $3270(93.0)$ & $784(95.6)$ & & $682(95.1)$ & $101(99.0)$ & \\
\hline \multirow[t]{7}{*}{ Pathological tumor stage } & pT0 & $227(5.2)$ & $197(5.6)$ & $30(3.7)$ & $<0.001$ & $29(4.0)$ & $1(1.0)$ & $<0.001$ \\
\hline & pTa & $123(2.8)$ & $108(3.1)$ & $15(1.8)$ & & $15(2.1)$ & $0(0.0)$ & \\
\hline & pTis & $424(9.8)$ & $353(10.0)$ & $71(8.7)$ & & $68(9.5)$ & $3(2.9)$ & \\
\hline & pT1 & $585(13.5)$ & $518(14.7)$ & $67(8.2)$ & & $65(9.1)$ & $2(2.0)$ & \\
\hline & pT2 & $1042(24.0)$ & $852(24.2)$ & $190(23.2)$ & & $175(24.4)$ & $15(14.7)$ & \\
\hline & pT3 & $1371(31.6)$ & $1062(30.2)$ & $309(37.7)$ & & $261(36.4)$ & $48(47.1)$ & \\
\hline & pT4 & $563(13.0)$ & $425(12.1)$ & $138(16.8)$ & & $105(14.6)$ & $33(32.4)$ & \\
\hline Soft tissue surgical margin status & positive & $262(6.0)$ & $89(5.4)$ & $73(8.9)$ & $<0.001$ & $57(7.9)$ & $16(15.7)$ & 0.017 \\
\hline Lymphovascular invasion & positive & $1475(34.0)$ & $1147(32.6)$ & $328(40.0)$ & $<0.001$ & $263(36.7)$ & $64(62.7)$ & $<0.001$ \\
\hline Concomitant Carcinoma in situ & positive & $2154(49.7)$ & $1741(49.5)$ & $413(50.4)$ & 0.695 & $364(50.8)$ & $49(48.0)$ & 0.682 \\
\hline No. of lymph nodes removed & mean $(\mathrm{SD})$ & $23.55(18.02)$ & $24.15(18.18)$ & $21.00(17.07)$ & $<0.001$ & $20.76(17.06)$ & $22.65(17.21)$ & 0.297 \\
\hline No. of positive lymph nodes & mean $(\mathrm{SD})$ & $1.25(4.61)$ & $1.25(4.58)$ & $1.27(4.75)$ & 0.886 & $1.03(4.82)$ & $2.98(3.89)$ & $<0.001$ \\
\hline Lymph node metastases & positive & $1127(26.0)$ & $906(25.8)$ & $221(27.0)$ & 0.518 & $152(21.2)$ & $69(67.6)$ & $<0.001$ \\
\hline Three-month mortality rate & yes & $140(3.2)$ & $0(0)$ & $140(17)$ & 0.001 & $88(12)$ & $11(11)$ & 0.8 \\
\hline
\end{tabular}

lymphovascular invasion, advanced tumor stage or higher clinical and pathologic tumor grade. Despite this higher rate of adverse pathologic features, AC was significantly less often administered in patients aged $\geq 75$ years $(12.4 \%$ vs. $25.1 \%, p<0.001)$.

Patients $\geq 75$ years old who were selected to receive $\mathrm{AC}$ had significant higher rates of advanced tumor stage, positive soft tissue surgical margins, lymphovascular invasion and lymph node metastasis (Table 1). The rate of thrombocytosis, perioperative blood transfusion, hypoalbuminemia as well as the three-months mortality rate was similar in patients $\geq 75$ years old that received adjuvant chemotherapy than in patients $\geq 75$ years old that did not receive $\mathrm{AC}$.

\section{Survival analyses}

Median follow up of patients alive was 42.4 months (IQR 18.3-85.1) for the entire cohort. The 5-year estimates for RFS, CSS and OS were $60.8 \%$ (95\%CI 59.1-62.5\%), 66.9\% (95\%CI 65.3-68.6\%) and $55.9 \%$ (95\%CI 54.2-57.6\%), respectively. On survival analyses, patients aged $\geq 75$ years had significantly worse survival outcomes with respect to RFS, CSS and OS compared to patients $<75$ years $(p<0.001$, Fig. 1).

\section{Effect of adjuvant chemotherapy}

On univariable survival analyses of the entire cohort, patients who had received AC had a significantly worse 5 -year CSS (47.3\% vs. $73.6 \%, p<$ $0.001)$ and 5 -year OS $(42.2 \%$ vs. $60.3 \%, p<0.001)$ in comparison to patient who had not received AC. 5-year RFS was found to be similar for both groups (60.5\% vs. $61.8 \%, p=0.37)$. In a subgroup analyses of patients aged $\geq 75$ years, patients who had received AC also suffered significantly worse 5-year RFS 

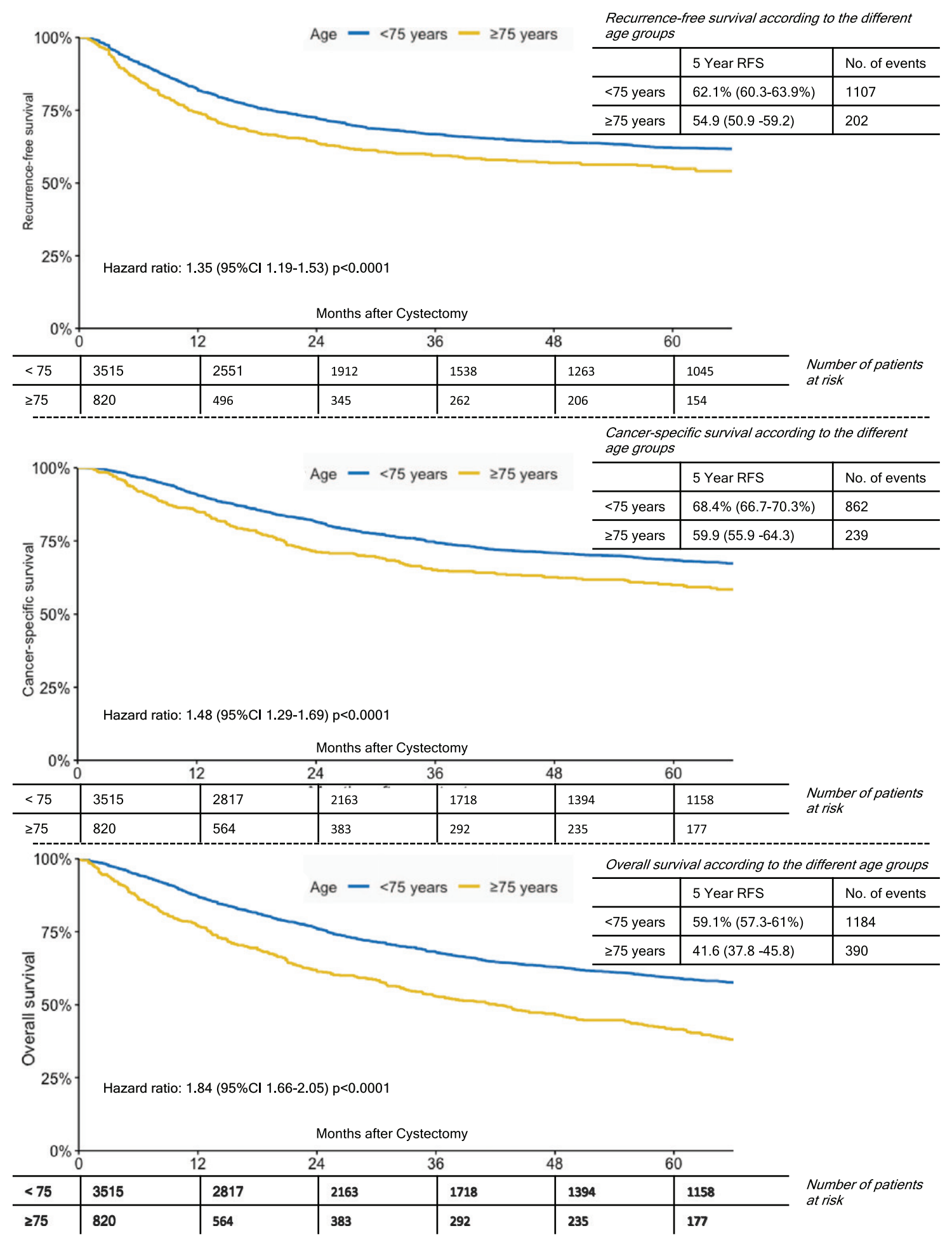

Fig. 1. Kaplan-Meier Curves for 5-Year Recurrence-Free Survival; Cancer-Specific Survival and Overall Survival by Age Groups (<75 vs. $\geq 75$ years old). 
(30.9\% vs. $58.1 \%, p<0.001)$, 5-year CSS (34.2\% vs. $64.2 \%, p<0.001)$ and 5 -year OS $(28.7 \%$ vs $43.6 \%$, $p=0.007)$.

In a subgroup analyses of patients $\geq 75$ years with lymph node metastases, patients who had received AC showed a significantly better 5-year OS (41\% vs. $30.9 \%, p=0.02$ ). While 5-year RFS and CSS were also favorable for patients who had received AC, this did not reach statistical significance (Fig. 2). For patients $\geq 75$ years with either $\geq \mathrm{pT} 3$ disease or any NOCD (non-organ confined disease), there were no significant group differences with respect to the administration of AC and survival outcomes (Figs. 3 and 4). In comparison, patients $<75$ years with lymph node metastases who had received AC also showed a significantly better 5-year RFS (32.1\% vs. $26.6 \%$, $p<0.001)$, 5 -year CSS $(38.2 \%$ vs. $31.5 \%, p=0.011)$ and 5-year OS (34.3 vs. $24.4 \%, p<0.001)$. However, again in patients $<75$ years with either $\geq \mathrm{pT} 3$ disease or any NOCD, there were no significant group differences with respect to the administration of $\mathrm{AC}$ and survival outcomes ( $p>0.05$ for all endpoints).

In a multivariable Cox model that was adjusted for several established outcome predictors, patients $\geq 75$ years who had received AC showed favorable survival outcomes with respect to OS compared to patients $\geq 75$ years who had not received AC (HR 0.75 [95\%CI 0.56-0.99] $p=0.045$, Table 2). This effect was even more pronounced in the subgroups of patients with either lymph node metastases (HR 0.64 [95\%CI 0.45-0.9] $p=0.011$ ) or $\geq \mathrm{pT} 3$ disease (HR 0.63 [95\%CI 0.46-0.86] $p=0.003$, Table 2). However, there was no significant effect on either RFS or CSS and the association remained insignificant in all further subgroup analyses. The same model in patients aged $<75$ years also showed a favorable effect for the administration of AC with respect to OS (HR 0.89 [95\%CI 0.79-1.0] $p=0.047$ ) and on subgroup analyses (lymph node metastases: HR 0.66 [95\% CI 0.56-0.79] $p<0.001 ; \geq$ pT3disease: HR 0.84 [95\% CI $0.73-0.96] p=0.013$ ). However, there was again no significant association between the administration of $\mathrm{AC}$ and RFS or CSS and the association remained insignificant in all further subgroup analyses.

\section{DISCUSSION}

Despite cumulative evidence to higher incidence and mortality in the ever-growing elderly population, there is very little data concerning the effectiveness of multimodal treatment strategies for UCB for these patients [19, 20,36]. With this retrospective analysis, we aimed to inform the debate concerning the optimal management of UCB in the elderly with real world evidence on the benefit of AC after RC. Management of UCB in the elderly should take into consideration that, while aging is in fact a heterogeneous process, many elderly patients are frail and their tumors show more aggressive behavior [19-21]. In our large multicenter database, we verified that elderly patients are more likely to suffer from advanced disease. Still, we found that elderly patients were less likely to receive AC. These findings are in line with previous findings by Leveridge et al., who analyzed the outcomes of 1,331 patients aged $\geq 75$ years undergoing $\mathrm{RC}$ for UCB from 1994 to 2008 [37].

On univariable survival analyses of patient aged $\geq 75$ years, we were not able to demonstrate a significant benefit for the administration of AC with respect to RFS, CSS or OS. Several previous studies that analyzed a non-age specific cohort had similar findings, and it was only on meta-analyses that a small, yet significant survival benefit could be demonstrated [22, $24,26]$. The likely explanation is that only patients with poor prognostic factors were selected for administration of $\mathrm{AC}$ and subsequently suffered worse survival outcomes due to advanced and aggressive disease. In a subgroup analysis of patients with lymph node metastases, we found favorable outcomes after the administration of $\mathrm{AC}$ with respect to OS. Contrary to data by Leveridge et al., in our study, this association did not reach statistical significance for RFS or $\geq$ pT3 disease. These conflicting results may be due to different cut off groups that were used for classification of age. Overall, our findings emphasize that the effect of AC in the elderly is significantly modified by the individual's risk of disease recurrence and optimal patient selection is of the utmost importance in clinical decision making.

After adjusting for established prognostic variables, we were able to demonstrate a significant favorable association between the administration of $\mathrm{AC}$ and $\mathrm{OS}$ on multivariable Cox regression analyses. This effect was even more pronounced in the subgroups of patients with either lymph node metastases or $\geq$ pT3 disease and similar to the effect in patients aged $<75$ years. While an OS benefit is arguably the most unambiguous and ultimately most important endpoint for many patients, it may not be the optimal endpoint in the elderly population and could potentially be affected by a selection bias. In contrary, even on subgroup analyses of patients with advanced disease there was no benefit with respect to RFS or CSS. 

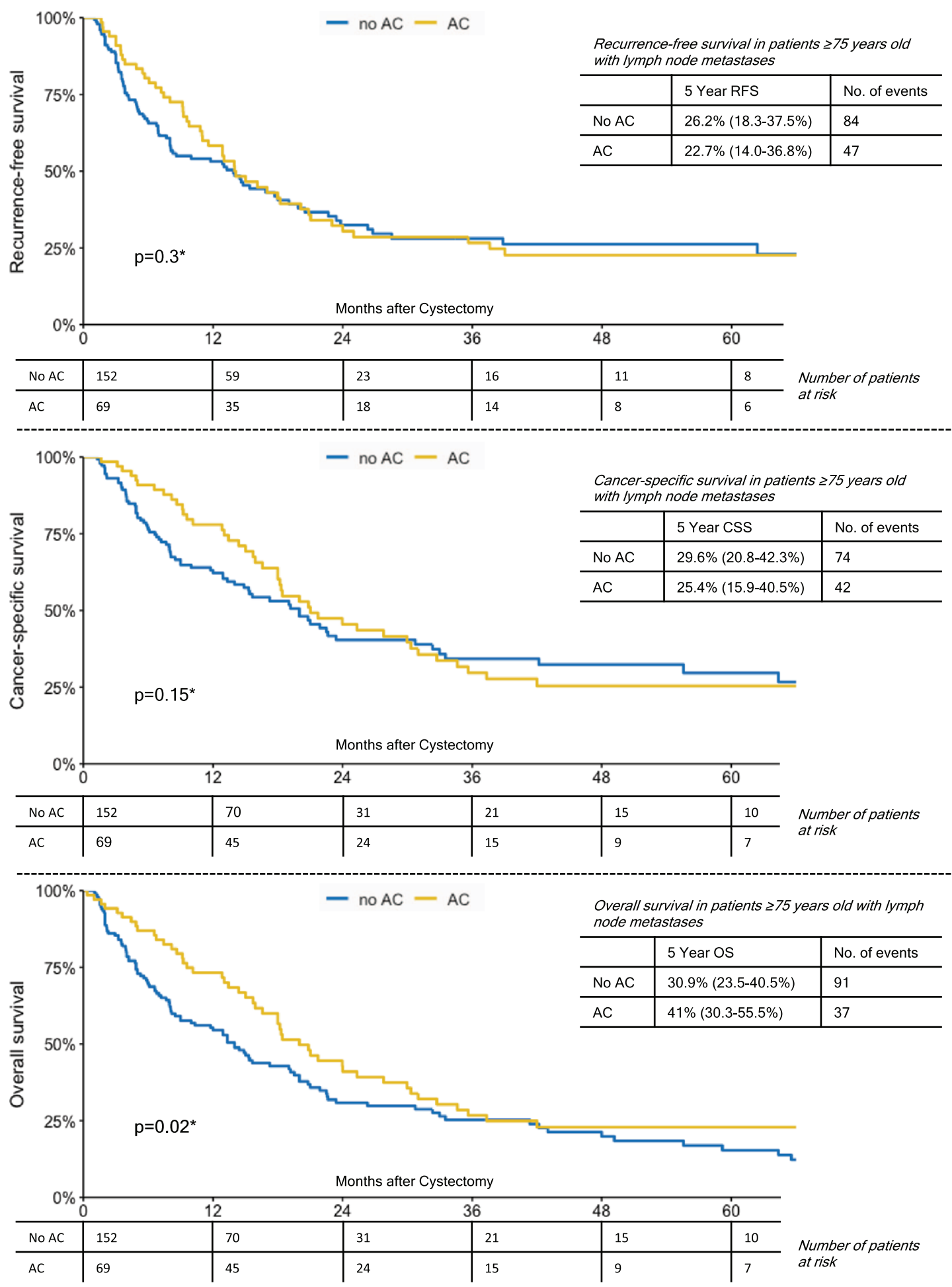

Fig. 2. Kaplan-Meier Curves Demonstrating The Effect of Adjuvant Chemotherapy on Recurrence-Free Survival; Cancer-Specific Survival and Overall Survival in Patients $\geq 75$ Years Old with Lymph Node Metastases. 

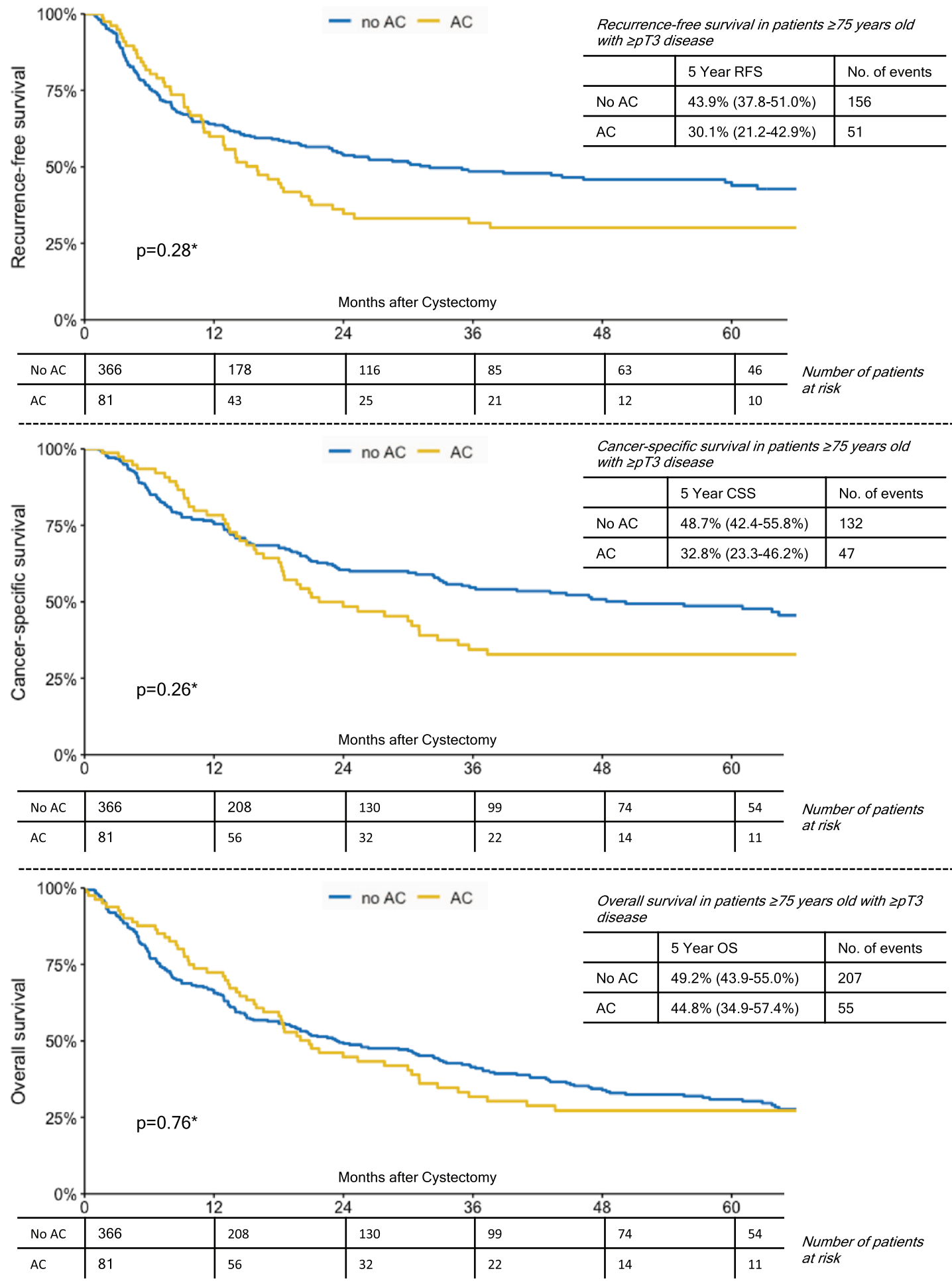

Fig. 3. Kaplan-Meier Curves Demonstrating The Effect of Adjuvant Chemotherapy on Recurrence-Free Survival; Cancer-Specific Survival and Overall Survival in Patients $\geq 75$ Years Old with $\geq$ pT3 Disease. 


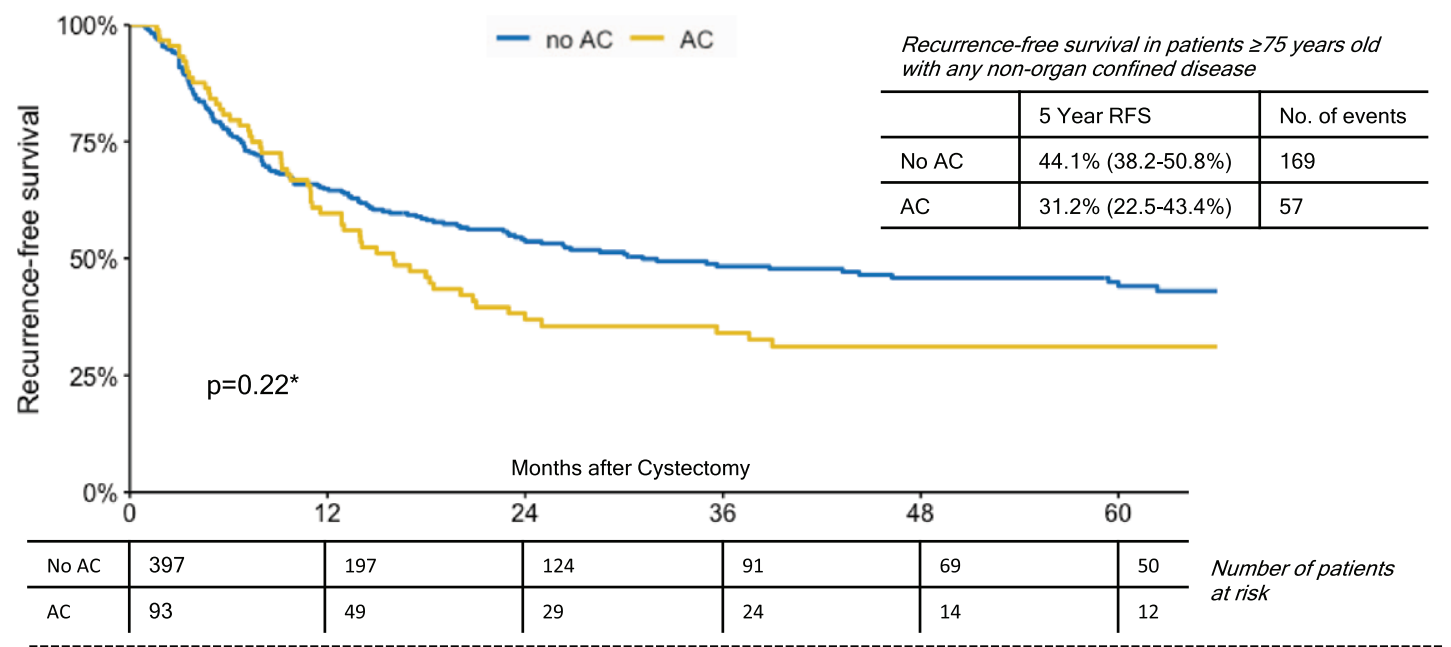

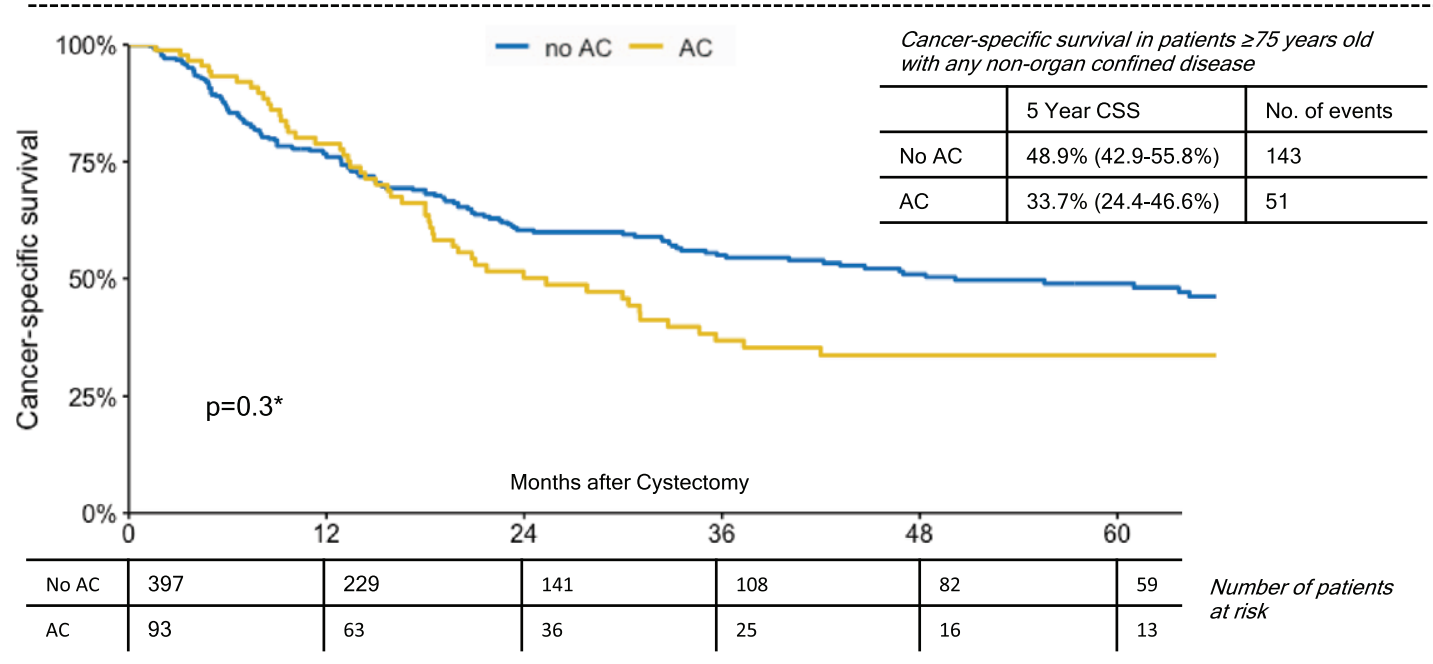

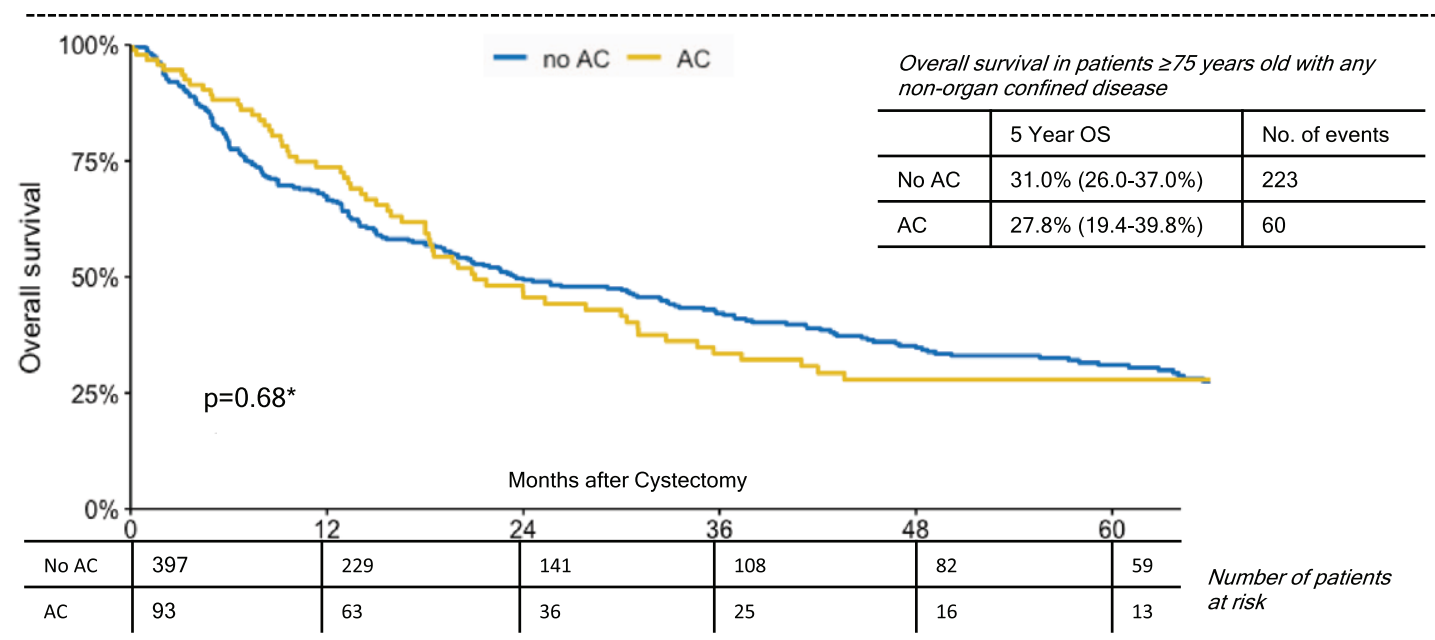

Fig. 4. Kaplan-Meier Curves Demonstrating the Effect of Adjuvant Chemotherapy on Recurrence-Free Survival; Cancer-Specific Survival and Overall Survival in Patients Over 75 Years with any Non-Organ Confined Disease. 
Table 2

Multivariable Cox Regression Analyses of the Association of Adjuvant Chemotherapy with Clinicopathologic Characteristics in 820 Patients $\geq 75$ Years Old Treated with Radical Cystectomy for Urothelial Carcinoma of the Bladder

\begin{tabular}{|c|c|c|c|c|c|c|c|c|c|c|c|}
\hline \multirow[t]{2}{*}{ Subgroups } & \multirow[t]{2}{*}{ Variable } & \multirow[t]{2}{*}{$n$} & \multicolumn{3}{|c|}{$\begin{array}{l}\text { Recurrence-free } \\
\text { Survival }\end{array}$} & \multicolumn{3}{|c|}{$\begin{array}{l}\text { Cancer-specific } \\
\text { Survival }\end{array}$} & \multicolumn{3}{|c|}{ Overall Survival } \\
\hline & & & $H R$ & $95 \% C I$ & $p$ & $H R$ & $95 \% C I$ & $p$ & $H R$ & $95 \% C I$ & $p$ \\
\hline \multirow[t]{7}{*}{$\begin{array}{l}\text { All patients } \geq 75 \text { years } \\
\quad \text { old }(n=820)\end{array}$} & $\begin{array}{l}\text { Use of adjuvant chemotherapy } \\
\quad(\text { Ref.: no) }\end{array}$ & 102 & 0.95 & $0.7-1.3$ & 0.77 & 0.85 & $0.61-1.2$ & 0.35 & 0.75 & $0.56-0.99$ & 0.045 \\
\hline & Gender (Ref.: female) & 621 & 0.97 & $0.74-1.3$ & 0.8 & 1.01 & $0.76-1.3$ & 0.96 & 1.01 & $0.83-1.25$ & 0.89 \\
\hline & $\geq \mathrm{pT} 3$ disease $(\operatorname{Ref} .:<p T 3)$ & 447 & 1.81 & $1.37-2.4$ & $<0.001$ & 2.15 & $1.58-2.9$ & $<0.001$ & 1.7 & $1.38-2.11$ & $<0.001$ \\
\hline & LNM (Ref.: negative) & 221 & 2.28 & $1.75-3.0$ & $<0.001$ & 2.62 & $1.98-3.5$ & $<0.001$ & 1.97 & $1.58-2.46$ & $<0.001$ \\
\hline & LVI (Ref.: negative) & 328 & 1.81 & $1.41-2.3$ & $<0.001$ & 1.8 & $1.38-2.4$ & $<0.001$ & 1.52 & $1.25-1.85$ & $<0.001$ \\
\hline & Surgical margins (Ref.: negative) & 73 & 1.41 & $1.02-1.9$ & 0.039 & 1.6 & $1.14-2.2$ & 0.006 & 1.2 & $0.89-1.61$ & 0.23 \\
\hline & CIS (Ref.: negative) & 413 & 0.96 & $0.76-1.2$ & 0.74 & 1.02 & $0.79-1.3$ & 0.88 & 1.25 & $1.04-1.5$ & 0.02 \\
\hline \multirow{5}{*}{$\begin{array}{l}\text { All patients } \geq 75 \text { years } \\
\text { old with lymph node } \\
\text { metastases }(n=221)\end{array}$} & $\begin{array}{l}\text { Use of adjuvant chemotherapy } \\
\quad(\text { Ref.: no) }\end{array}$ & 69 & 0.85 & $0.59-1.2$ & 0.39 & 0.75 & $0.51-1.1$ & 0.14 & 0.64 & $0.45-0.9$ & 0.011 \\
\hline & Gender (Ref.: female) & 164 & 0.83 & $0.57-1.2$ & 0.35 & 0.89 & $0.59-1.3$ & 0.55 & 1.16 & $0.8-1.7$ & 0.44 \\
\hline & $\geq \mathrm{pT} 3$ disease $(\operatorname{Ref.:}<p T 3)$ & 178 & 1.93 & $1.17-3.2$ & 0.01 & 2.33 & $1.33-4.1$ & 0.003 & 2.27 & $1.42-3.6$ & $<0.001$ \\
\hline & Surgical margins (Ref.: negative) & 42 & 1.37 & $0.91-2.1$ & 0.126 & 1.72 & $1.13-2.6$ & 0.012 & 1.45 & $0.99-2.1$ & 0.055 \\
\hline & CIS (Ref.: negative) & 109 & 0.93 & $0.65-1.3$ & 0.68 & 0.9 & $0.62-1.3$ & 0.6 & 1.02 & $0.73-1.4$ & 0.91 \\
\hline \multirow{6}{*}{$\begin{array}{l}\text { All patients } \geq 75 \text { years } \\
\text { old with } \geq \mathrm{pT} 3 \text { disease } \\
\quad(n=447)\end{array}$} & $\begin{array}{l}\text { Use of adjuvant chemotherapy } \\
\quad(\text { Ref.: no) }\end{array}$ & 81 & 0.78 & $0.56-1.1$ & 0.15 & 0.72 & $0.5-1.0$ & 0.071 & 0.63 & $0.46-0.86$ & 0.003 \\
\hline & Gender (Ref.: female) & 341 & 1.06 & $0.77-1.4$ & 0.83 & 1.13 & $0.81-1.6$ & 0.48 & 1.24 & $0.94-1.63$ & 0.13 \\
\hline & LNM (Ref.: negative) & 178 & 2.41 & $1.79-3.3$ & $<0.001$ & 2.77 & $2.01-3.8$ & $<0.001$ & 2.15 & $1.66-2.79$ & $<0.001$ \\
\hline & LVI (Ref.: negative) & 252 & 2.08 & $1.54-2.8$ & $<0.001$ & 2.17 & $1.58-3.0$ & $<0.001$ & 1.82 & $1.42-2.34$ & $<0.001$ \\
\hline & Surgical margins (Ref.: negative) & 62 & 1.4 & $1.0-2.0$ & 0.052 & 1.58 & $1.12-2.2$ & 0.01 & 1.18 & $0.86-1.61$ & 0.3 \\
\hline & CIS (Ref.: negative) & 193 & 0.91 & $0.69-1.2$ & 0.52 & 0.97 & $0.72-1.3$ & 0.83 & 1.17 & $0.92-1.48$ & 0.2 \\
\hline
\end{tabular}

Ref. $=$ Reference, $L N M=$ Lymph Node Metastases, $C I S=$ Carcinoma in situ, $L V I=$ Lymphovascular invasion, $H R=$ Hazard ratio $95 \% C I=95 \%$ Confidence interval, $p=P$-Value.

These conflicting results may be due to the fact that the optimal chemotherapeutic regimen for elderly patients in this specific setting remains unknown. A recent non-age specific meta-analysis of the benefit of AC reported that only the regimen of cisplatin, gemcitabine and paclitaxel is associated with significant improvement in both RFS and OS [38]. However, patients aged $\geq 70$ years are known to be less likely to receive cisplatin-based chemotherapy than younger patients [37]. However, just like the curative treatment of RC should not be withheld from elderly patients, they should also not be withheld a potentially life-saving AC only based on chronological age alone. The treatment of UCB in the elderly should be individualized, focusing on biological age and performance status $[19,20]$. A multidisciplinary approach and a geriatric evaluation are needed to identify patients eligible for AC [20]. Our study shows further trials concerning the optimal chemotherapeutic regimen and the value of presumably more tolerable agents, such as non-cisplatin-based chemotherapy, are required to investigate adjuvant treatment strategies in the management of UCB in the elderly. The demonstrated inefficacy of AC to improve RFS or CSS in the elderly population also warrants the investigation of the benefit of novel immunotherapeutic drugs in the adjuvant and neoadjuvant setting, as such agents might demonstrate a more compelling clinical net-benefit for all endpoints and thus change clinical practice.

While the strength of this cohort is its homogeneity in treatment allocation and its international, multicenter nature, the study is limited by its retrospective design and the short median follow-up of 42.4 months. However, previous data suggest that over two-third of patients experience disease recurrence after RC within 12 months and $\geq 90 \%$ within 24 months [39]. We do not have any data, why patients who had an indication for administration of $\mathrm{AC}$ did not receive it. This could reflect a selection bias. Nevertheless, we feel that this does not necessarily contradict our main finding, which is that optimal patient selection is necessary to identify patients who are most likely to tolerate and benefit from AC. Another limitation is the missing information concerning the specific chemotherapeutic regimen administered and about the administration of deferred chemotherapy at time of recurrence. Furthermore, more appropriate endpoints such as quality of life or as functional independence would be preferable 
in the elderly population [40]. Well-designed, randomized trials would be superior to fully establish the administration of AC in the elderly population and further improve patient selection, however, the advent of novel agents suggests that such a randomized clinical trial is unlikely to ever be successfully concluded.

\section{CONCLUSION}

In this large observational study, AC was associated with improved OS, but not RFS or CSS, in elderly patients treated with RC for UCB. This is of clinical importance, as elderly patients are more likely to have adverse pathologic features and experience worse survival outcomes. Treatment of UCB should include both a multidisciplinary approach and a geriatric evaluation to identify patients who are most likely to tolerate and benefit from AC. Elderly patients should not be precluded from AC due to their chronological age alone.

\section{ACKNOWLEDGMENTS}

Victor Schüttfort, Benjamin Pradere and Ekaterina Laukhtina are supported by the EUSP Scholarship of the European Association of Urology (EAU). Other than that, the authors have no acknowledgments.

\section{FUNDING}

The authors report no funding.

\section{AUTHOR CONTRIBUTIONS}

All authors have made substantial contributions to the work, have approved the final version to be published and have agreed to be accountable for the accuracy and integrity of the work. Victor $M$. Schuettfort - conception; performance of work; interpretation and analysis of data; writing the article. Benjamin Pradere - interpretation and analysis of data; writing the article. Hadi Mostafaei - interpretation and analysis of data; writing the article. Ekaterina Laukhtina - interpretation and analysis of data; writing the article. Keiichiro Mori - interpretation and analysis of data; writing the article. Fahad Quhal - interpretation and analysis of data; writing the article. Reza Sari Motlagh - interpretation and analysis of data; writing the article. Michael Rink - interpretation and analysis of data; writing the article. Pierre I. Karakiewicz - interpretation and analysis of data; writing the article. Marina Deuker - interpretation and analysis of data; writing the article. Marco Moschini - interpretation and analysis of data; writing the article. Lara Franziska Stolzenbach - interpretation and analysis of data; writing the article. Quoc-Dien Trinh - interpretation and analysis of data; writing the article. Alberto Briganti - interpretation and analysis of data; writing the article. David D'Andrea - interpretation and analysis of data; writing the article. Shahrokh F. Shariat - conception; performance of work; interpretation and analysis of data; writing the article.

\section{CONFLICT OF INTEREST}

S.F. Shariat reports advisory board of/and or speaker for Astellas, Astra Zeneca, Bayer, BMS, Cepheid, Ferring, Ipsen, Janssen, Lissy, MSD, Olympus, Pfizer, Pierre Fabre, Roche, Sanochemia and Sanofi. Victor Schuettfort, Benjamin Pradere, Hadi Mostafaei, Ekaterina Laukhtina, Keiichiro Mori, Fahad Quhal, Reza Sari Motlagh, Michael Rink, Pierre Karakiewicz, Marina Deuker, Marco Moschini, Lara Stolzenbach, Quoc-Dien Trinh, Alberto Briganti and David D'Andrea have no conflicts of interest.

\section{REFERENCES}

[1] Witjes J, Bruins M, Cathomas R, Compérat R, Cowan N, Gakis G, et al. EAU Guidelines on Muscle-invasive and Metastatic Bladder Cancer. EAU Guidelines 2019(2019 Edn).

[2] Ploussard G, Shariat SF, Dragomir A, Kluth LA, Xylinas E, Masson-Lecomte A, et al. Conditional survival after radical cystectomy for bladder cancer: evidence for a patient changing risk profile over time. Eur Urol. 2014;66(2):361-70.

[3] Grossman HB, Natale RB, Tangen CM, Speights VO, Vogelzang NJ, Trump DL, et al. Neoadjuvant chemotherapy plus cystectomy compared with cystectomy alone for locally advanced bladder cancer. N Engl J Med. 2003;349(9): 859-66.

[4] Svatek RS, Shariat SF, Novara G, Skinner EC, Fradet Y, Bastian PJ, et al. Discrepancy between clinical and pathological stage: external validation of the impact on prognosis in an international radical cystectomy cohort. BJU Int. 2011;107(6):898-904.

[5] Svatek RS, Shariat SF, Lasky RE, Skinner EC, Novara G, Lerner SP, et al. The effectiveness of off-protocol adjuvant chemotherapy for patients with urothelial carcinoma of the urinary bladder. Clin Cancer Res. 2010;16(17):4461-7.

[6] Shariat SF, Chade DC, Karakiewicz PI, Ashfaq R, Isbarn H, Fradet Y, et al. Combination of multiple molecular markers can improve prognostication in patients with locally advanced and lymph node positive bladder cancer. J Urol. 2010;183(1):68-75. 
[7] Shariat SF, Lotan Y, Vickers A, Karakiewicz PI, SchmitzDrager BJ, Goebell PJ, et al. Statistical consideration for clinical biomarker research in bladder cancer. Urol Oncol. 2010;28(4):389-400.

[8] Motterle G, Andrews JR, Morlacco A, Karnes RJ. Predicting Response to Neoadjuvant Chemotherapy in Bladder Cancer. Eur Urol Focus. 2019.

[9] Rink M, Chun FK, Dahlem R, Soave A, Minner S, Hansen $\mathrm{J}$, et al. Prognostic role and HER2 expression of circulating tumor cells in peripheral blood of patients prior to radical cystectomy: a prospective study. Eur Urol. 2012;61(4): 810-7.

[10] Xylinas E, Robinson BD, Kluth LA, Volkmer BG, Hautmann R, Küfer R, et al. Association of T-cell co-regulatory protein expression with clinical outcomes following radical cystectomy for urothelial carcinoma of the bladder. Eur J Surg Oncol. 2014;40(1):121-7.

[11] Mir C, Shariat SF, van der Kwast TH, Ashfaq R, Lotan $\mathrm{Y}$, Evans A, et al. Loss of androgen receptor expression is not associated with pathological stage, grade, gender or outcome in bladder cancer: a large multi-institutional study. BJU Int. 2011;108(1):24-30.

[12] Shariat SF, Ashfaq R, Sagalowsky AI, Lotan Y. Correlation of cyclin D1 and E1 expression with bladder cancer presence, invasion, progression, and metastasis. Hum Pathol. 2006;37(12):1568-76.

[13] Soria F, Krabbe LM, Todenhofer T, Dobruch J, Mitra AP, Inman BA, et al. Molecular markers in bladder cancer. World J Urol. 2019;37(1):31-40.

[14] Mari A, Campi R, Tellini R, Gandaglia G, Albisinni S, Abufaraj $\mathrm{M}$, et al. Patterns and predictors of recurrence after open radical cystectomy for bladder cancer: a comprehensive review of the literature. World J Urol. 2018;36(2): 157-70.

[15] Novara G, Svatek RS, Karakiewicz PI, Skinner E, Ficarra V, Fradet Y, et al. Soft tissue surgical margin status is a powerful predictor of outcomes after radical cystectomy: a multicenter study of more than 4,400 patients. J Urol. 2010;183(6):2165-70.

[16] Advanced Bladder Cancer Meta-analysis C. Neoadjuvant chemotherapy in invasive bladder cancer: update of a systematic review and meta-analysis of individual patient data advanced bladder cancer (ABC) meta-analysis collaboration. Eur Urol. 2005;48(2):202-5; discussion 5-6.

[17] Griffiths G, Hall R, Sylvester R, Raghavan D, Parmar MK. International phase III trial assessing neoadjuvant cisplatin, methotrexate, and vinblastine chemotherapy for muscleinvasive bladder cancer: long-term results of the BA06 30894 trial. J Clin Oncol. 2011;29(16):2171-7.

[18] Hermans TJN, Fransen van de Putte EE, Horenblas S, Lemmens V, Aben K, van der Heijden MS, et al. Perioperative treatment and radical cystectomy for bladder cancer-a population based trend analysis of 10,338 patients in the Netherlands. Eur J Cancer. 2016;54:18-26.

[19] Shariat SF, Milowsky M, Droller MJ. Bladder cancer in the elderly. Urol Oncol. 2009;27(6):653-67.

[20] Soria F, Moschini M, Korn S, Shariat SF. How to optimally manage elderly bladder cancer patients? Transl Androl Urol. 2016;5(5):683-91.

[21] Fonteyne V, Ost P, Bellmunt J, Droz JP, Mongiat-Artus P, Inman B, et al. Curative Treatment for Muscle Invasive Bladder Cancer in Elderly Patients: A Systematic Review. Eur Urol. 2018;73(1):40-50.

[22] Leow JJ, Martin-Doyle W, Rajagopal PS, Patel CG, Anderson EM, Rothman AT, et al. Adjuvant chemotherapy for invasive bladder cancer: a 2013 updated systematic review and meta-analysis of randomized trials. Eur Urol. 2014;66(1):42-54.

[23] Galsky MD, Stensland KD, Moshier E, Sfakianos JP, McBride RB, Tsao CK, et al. Effectiveness of Adjuvant Chemotherapy for Locally Advanced Bladder Cancer. J Clin Oncol. 2016;34(8):825-32.

[24] Lehmann J, Franzaring L, Thuroff J, Wellek S, Stockle M. Complete long-term survival data from a trial of adjuvant chemotherapy vs control after radical cystectomy for locally advanced bladder cancer. BJU Int. 2006;97(1): 42-7.

[25] Sternberg CN, Skoneczna I, Kerst JM, Albers P, Fossa SD, Agerbaek M, et al. Immediate versus deferred chemotherapy after radical cystectomy in patients with pT3-pT4 or $N+$ M0 urothelial carcinoma of the bladder (EORTC 30994): an intergroup, open-label, randomised phase 3 trial. Lancet Oncol. 2015;16(1):76-86.

[26] Cognetti F, Ruggeri EM, Felici A, Gallucci M, Muto G, Pollera CF, et al. Adjuvant chemotherapy with cisplatin and gemcitabine versus chemotherapy at relapse in patients with muscle-invasive bladder cancer submitted to radical cystectomy: an Italian, multicenter, randomized phase III trial. Ann Oncol. 2012;23(3):695-700.

[27] Lucca I, Roupret M, Kluth L, Rink M, Tilki D, Fajkovic $\mathrm{H}$, et al. Adjuvant cisplatin-based combined chemotherapy for lymph node (LN)-positive urothelial carcinoma of the bladder (UCB) after radical cystectomy (RC): a retrospective international study of $>1500$ patients. BJU Int. 2015;115(5):722-7.

[28] Vetterlein MW, Seisen T, May M, Nuhn P, Gierth M, Mayr R, et al. Effectiveness of Adjuvant Chemotherapy After Radical Cystectomy for Locally Advanced and/or Pelvic Lymph Node-Positive Muscle-invasive Urothelial Carcinoma of the Bladder: A Propensity Score-Weighted Competing Risks Analysis. Eur Urol Focus. 2018;4(2):252-9.

[29] Bamias A, Efstathiou E, Moulopoulos LA, Gika D, Hamilos G, Zorzou MP, et al. The outcome of elderly patients with advanced urothelial carcinoma after platinumbased combination chemotherapy. Ann Oncol. 2005;16(2): 307-13.

[30] Nielsen ME, Shariat SF, Karakiewicz PI, Lotan Y, Rogers CG, Amiel GE, et al. Advanced age is associated with poorer bladder cancer-specific survival in patients treated with radical cystectomy. Eur Urol. 2007;51(3):699-706; discussion -8.

[31] Shariat SF, Kim J, Raptidis G, Ayala GE, Lerner SP. Association of p53 and p21 expression with clinical outcome in patients with carcinoma in situ of the urinary bladder. Urology. 2003;61(6):1140-5.

[32] Xylinas E, Rink M, Robinson BD, Lotan Y, Babjuk M, Brisuda A, et al. Impact of histological variants on oncological outcomes of patients with urothelial carcinoma of the bladder treated with radical cystectomy. Eur J Cancer. 2013;49(8):1889-97.

[33] Shariat SF, Khoddami SM, Saboorian H, Koeneman KS, Sagalowsky AI, Cadeddu JA, et al. Lymphovascular invasion is a pathological feature of biologically aggressive disease in patients treated with radical prostatectomy. J Urol. 2004;171(3):1122-7.

[34] Rink M, Fajkovic H, Cha EK, Gupta A, Karakiewicz PI, Chun FK, et al. Death certificates are valid for the determination of cause of death in patients with upper and lower tract urothelial carcinoma. Eur Urol. 2012;61(4): 854-5. 
[35] Karadeniz P, Ercan I. Examining tests for comparing survival curves with right censored data. Statistics in Transition New Series. 2017;18:311-28.

[36] Bray F, Ferlay J, Soerjomataram I, Siegel RL, Torre LA, Jemal A. Global cancer statistics 2018: GLOBOCAN estimates of incidence and mortality worldwide for 36 cancers in 185 countries. CA Cancer J Clin. 2018;68(6):394-424.

[37] Leveridge MJ, Siemens DR, Mackillop WJ, Peng Y, Tannock IF, Berman DM, et al. Radical cystectomy and adjuvant chemotherapy for bladder cancer in the elderly: a population-based study. Urology. 2015;85(4):791-8.
[38] Kim HS, Jeong CW, Kwak C, Kim HH, Ku JH. Adjuvant chemotherapy for muscle-invasive bladder cancer: a systematic review and network meta-analysis of randomized clinical trials. Oncotarget. 2017;8(46):81204-14.

[39] Rink M, Lee DJ, Kent M, Xylinas E, Fritsche HM, Babjuk M, et al. Predictors of cancer-specific mortality after disease recurrence following radical cystectomy. BJU Int. 2013;111(3 Pt B):E30-6.

[40] Whelehan S, Lynch O, Treacy N, Gleeson C, Oates A, O'Donovan A. Optimising Clinical Trial Design in Older Cancer Patients. Geriatrics (Basel). 2018;3(3). 